\title{
SISTEMAS DE REPUTAÇÃO: UM CASO DE SIMULAÇÃO SOCIAL EM NARRATIVAS INTERATIVAS.
}

\section{REPUTATION SYSTEMS: A CASE OF SOCIAL SIMULATION IN INTERACTIVE NARRATIVES.}

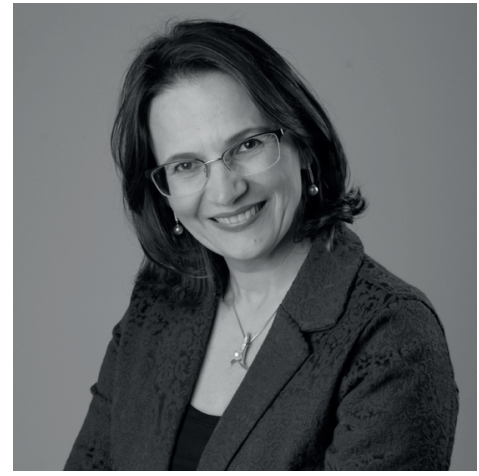

Gertrudes Aparecida Dandolini

Doutora em Engenharia de Produção

Universidade Federal de Santa Catarina gertrudes.dandolini@ufsc.br

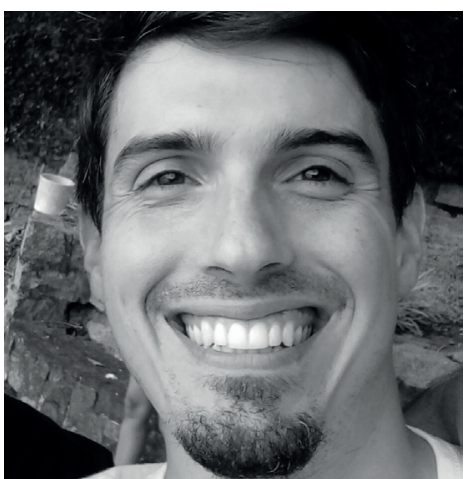

Rafael Mariano Caetano Arrivabene, Mestrando em Engenharia e Gestão do Conhecimento Universidade Federal de Santa Catarina rafael.arrivabene@gmail.com 


\section{RESUMO}

As narrativas interativas presentes nos jogos digitais atuais, se passam em ambientes sociais cada vez mais detalhados. Nestes enredos, os jogadores podem explorar situações e comportamentos sociais complexos, através de simulações de tais fenômenos. Sendo toda simulação uma redução arbitrária de um sistema maior, cabe questionar como fenômenos sociais podem ser simulados em jogos. Com o objetivo de entender este tipo de representação, o presente artigo analisa o fenômeno social da reputação como sendo um sistema, e então o compara com duas representações de tal sistema encontradas nos jogos digitais Dragon Age: Inquisition e Fable III. Conclui-se que as simulações nos jogos podem ser entendidas como traduções criativas dos sistemas complexos que representam, orientadas mais para as necessidades narrativas do jogo do que para o realismo do fenômeno.

\section{PALAVRAS-CHAVE}

Sistemas de Reputação; Simulação Social; Video Games; TGS.

\section{ABSTRACT}

The interactive narratives present in today's digital games, happen in increasingly detailed social environments. In these scenarios, players can explore complex social situations and behaviors through simulations of such phenomena. As any simulation is an arbitrary reduction of a bigger system, it is questioned how social phenomena can be simulated in games. With the goal to understand this kind of representation, this article analyses the social reputation phenomenon as a system, then compares it with two of its representations found in the digital games Dragon Age: Inquisition and Fable III. The conclusion is that simulations in games can be understood as creative translations of the complex systems they represent, oriented more to the narrative needs of the game than to the realism of the phenomenon.

\section{KEYWORDS}

Reputation Systems; Social Simulation; Video Games; GST.

\section{SIMULAÇÕES E JOGOS COMO REPRESENTAÇÕES INTERATIVAS}

Os estudos sobre simulações sociais vem se intensificando desde os anos 70, despertando interesse de áreas diversas, como economia, psicologia, educação e administração (INBAR, 1970; CROOKALL, 2000) além de matemática e infor- 
mática. O embrião da simulação social pode ser encontrado na Teoria dos Jogos de Von Neumann e Morgenstern, proposta em 1944. Esta teoria busca explicar o comportamento econômico humano a partir da modelagem matemática do processo decisório de seres inteligentes que enfrentam dilemas. Os dilemas, entretanto, são formas muito simples de jogos, onde os participantes devem tentar maximizar seus ganhos ao escolher a melhor ação dentre as disponíveis, levando em consideração a possível escolha do outro. Testes controlados, feitos com participantes humanos, poderiam então validar os modelos propostos, caracterizando-os como simulações. Com o passar do tempo, esta teoria, as simulações e os jogos, tornaram-se assuntos distintos, cada qual definindo uma área de estudo própria.

Segundo a educadora Margareth Gredler (2004) uma simulação "é um estudo de caso evolutivo de uma realidade social ou física em particular". São situações de final aberto que tentam representar uma realidade ao reproduzir as relações entre as variáveis observadas no sistema real e permitir que seus participantes experimentem os efeitos de suas ações e decisões. Também os jogos são situações de final aberto onde os participantes experimentam os efeitos de suas ações. Porém, nestes há geralmente a presença de um resultado quantificável, mais ou menos desejável. Há um objetivo, que por sua vez, sugere estratégias para alcançá-lo (SALEN, ZIMMERMAN, 2012). Pode-se considerar também que nem todos os jogos são representações explícitas de uma realidade objetiva, mas tal qual pinturas abstratas, também estes podem ser entendidos como representações de uma imagem mental, de uma ideia, mais do que de um fato. Vistos desta forma, simulações e jogos podem ser entendidos como diferentes, mas similares formas de representação interativa. Porém, enquanto simulações preocupam-se em modelar fielmente um sistema real (ROBINSON, 2015), os jogos têm o objetivo principal de entreter (DORMANS, 2011). A intersecção entre as duas formas se dá principalmente nos chamados jogos sérios que buscam ensinar e transmitir conhecimentos reais utilizando elementos divertidos e nos jogos de entretenimento que se apoiam em conhecimentos reais para criarem experiências divertidas. Enquanto o segundo caso pode ser exemplificado na imagem do xadrez, uma atividade lúdica que representa a configuração da sociedade medieval e suas guerras, o primeiro caso poderia ser identificado nos chamados wargames. Que são jogos de tabuleiro de guerra complexos que já foram utilizados com propósito de melhorar o planejamento estratégico de exércitos (GREDLER, 2004).

Ambos representam o fenômeno da guerra através de experiências interativas 
e suas regras. Porém, como seus objetivos são diferentes, também variam os detalhes de cada representação. Uma das tarefas mais difíceis na modelagem de simulações é justamente saber quais aspectos da realidade devem ser simulados e como. Há um número infinito de possíveis modelos de uma mesma realidade, podendo variar tanto de complexidade como até mesmo de conteúdo. Fatores que influenciam esta decisão são principalmente o conhecimento que se tem sobre o sistema real; a disponibilidade de tempo e recursos para o desenvolvimento da simulação; e evidentemente os objetivos desta (ROBINSON, 2015).

Por definição, nenhuma forma de representação é capaz de transmitir a totalidade do fenômeno que representa, sob risco de se igualar ao próprio fenômeno. "Uma simulação é uma representação de um sistema fonte via um sistema menos complexo", que informa o usuário sobre o primeiro (BOGOST, 2008). Neste sentido, o game designer Joris Dormans (2011), defende que o potencial dos jogos não reside em representar realisticamente as características de mundos fictícios, mas sim em capturar e transmitir a essência do funcionamento de sistemas complexos através de regras mais simples. Ambos os autores, Dormans e Bogost, concordam que esta forma de representação comporta um grau de intencionalidade do autor e preocupação deste com a função da simulação para o usuário. Assim, pode-se entender que o ato de escolher as variáveis, objetos e processos de um determinado sistema, para figurarem em sua simulação, é um ato de interpretação deste sistema por parte do observador (ALVES, 2008). O interesse desta pesquisa centra-se nesta característica interpretativa e consequentemente criativa da simulação de situações sociais em jogos digitais de entretenimento.

Os mundos fantásticos onde os personagens de jogos habitam e nos quais os jogadores imergem vêm ganhando contornos cada vez mais complexos, em especial nos Role Playing Games (RPGs). Na esperança de parecerem reais o suficiente para que o público os aceite, tais mundos fictícios apresentam mitologia, história, personagens e estruturas sociais ricas em detalhes (HONG, 2015). Além do controle da movimentação e ações dos protagonistas, a imersão se intensifica com a simulação de interações sociais variadas. Em muitas destas aventuras épicas, além de lutar contra os vilões, é possível exercer alguma profissão, negociar bens e propriedades, consumir drogas, ter relações sexuais e mesmo constituir família com personagens não-jogáveis (NPCs). Como tais jogos não se apegam em uma premissa de serem exatamente fiéis à realidade, tornam-se casos exemplares de como os objetivos dos criadores podem determinar as características destas representações.

Dentre estas várias situações sociais incorporadas em jogos recentes, o fenôme- 
no da reputação se mostrou como mais pertinente para este estudo. Reputação, na vida cotidiana parece ser algo extremamente subjetivo, ambíguo e etéreo, que emerge de um sistema de interrelações pessoais complexo. Entretanto, em jogos digitais, a reputação parece ser muito mais palpável. Uma variável sempre presente e inequívoca. A fim de observar diferentes maneiras de representação deste sistema, foram selecionados e analisados dois títulos de RPGs digitais, onde o fenômeno da reputação desempenha papel importante na narrativa.

Este estudo busca compreender como sistemas sociais complexos são representados em jogos digitais através de simulações. A pesquisa foi dividida em duas etapas. A primeira consistia em compreender como a reputação ocorre na natureza social, modelando-a como um sistema (ROBINSON, 2015). Nesta etapa foi conduzida uma pesquisa exploratória no formato de revisão sistemática da literatura (GALVÃO et al., 2004). Os objetivos da revisão foram (1) obter uma definição para o conceito de reputação através de diferentes disciplinas e (2) identificar os componentes mais comuns em modelos de sistemas de reputação. A segunda etapa, foi a aplicação deste modelo genérico nos casos específicos identificados nos jogos selecionados, e por fim a comparação entre os casos.

2. Estrutura de um Sistema de Reputação

Sistema é entendido aqui segundo a definição do Professor João Bosco da Mota Alves, o qual afirma que um sistema é "uma construção mental de uma organização contendo uma coleção de objetos inter-relacionados em uma dada estrutura perfazendo um todo (uma unidade) com alguma funcionalidade que o identifica como tal" (ALVES, 2012, p. 96). Agrupa-sea este conceito o de reputação, que é uma avaliação, simultaneamente quantitativa e qualitativa, da fama ou conceito que são atribuídos a algo ou alguém por um grupo de indivíduos (LEWIS, SHORT, 1879; BUENO, 1996 p.570; GOOGLE, 2017). Ela surge quando alguém deposita confiança em outro, baseando-se na probabilidade de que este não trairá sua confiança (WHITMEYER, 2000). Um sistema de reputação pode ser entendido como um conjunto de procedimentos que coleta, distribui e agrega avaliações sobre as atividades dos participantes de um sistema maior, formando um histórico de suas interações. Isto ajuda os indivíduos a controlarem suas expectativas com relação aos outros (RESNICK et al. 2000).

Um Sistema de Reputação está inserido em um supersistema social, o qual agrega também vários outros sistemas comuns à vida em sociedade, como economia, cultura, governo, etc. Definindo os objetos que compõem o Sistema de Reputação, é possível identificá-lo e separá-lo deste ambiente. Ele estrutura-se em dois elementos principais: os indivíduos e a comunicação (WEINBERG, DA- 
VIS, 2005; CHARNESS et al., 2011; SAEEDI, 2012; BERNARD, 2015). Geralmente cada indivíduo atua tanto como avaliador quanto como avaliado (RESNICK et al. 2000). Porém, como a reputação é uma medida individual, o sistema torna-se mais claro ao focar no indivíduo que está sendo avaliado. Esta peça prioritária do sistema será chamada aqui de Sujeito. Nas narrativas, o sujeito reputado, geralmente será o protagonista da história.

A reputação de um Sujeito está ligada a suas ações. Mesmo nos casos de reciprocidade indireta ou na possibilidade de uma reputação herdada (Tanimoto, 2007), a origem da confiança parte de alguma ação que é atribuída ao Sujeito, mesmo quando não executada por ele (CHARNESS et al., 2011; Ye et al., 2014). Nas simulações encontradas nesta revisão, a reputação sempre leva em consideração alguma variável que represente, pelo menos os resultados das ações do Sujeito. Se há ação, presume-se então a existência de um objeto desta ação. Algo sobre o qual o Sujeito age, ensejando sua avaliação. No modelo desenvolvido por Saeedi (2012), os compradores no site eBay avaliam os vendedores segundo uma função de utilidade que incorpora variáveis como a qualidade da venda e dos produtos vendidos. Mas o objeto pode estar fundido com outros elementos do sistema, como nos casos da ação do sujeito sobre si mesmo, a ação direta do Sujeito sobre seu avaliador, ou mesmo da ação do Sujeito sobre e por meio da própria comunicação (Tanimoto, 2007; BERNARD, 2015).

A comunicação é um tecido que une os elementos e conduz os processos dentro do Sistema de Reputação. Não há avaliação sobre um fato que não foi percebido, portanto, não há reputação para o Sujeito de tal ação. Por outro lado, boatos e calúnias podem incitar julgamentos sobre um Sujeito, conferindo-lhe uma reputação, ainda que desmerecida (WEINBERG, DAVIS, 2005; Ye et al., 2014). Todos os Sistemas de Reputação estudados baseiam-se na possibilidade da comunicação entre os indivíduos, seja na comunicação direta entre o Sujeito e seu avaliador, na forma de um histórico das ações do Sujeito, ou na comunicação recíproca e difusa entre os membros de uma comunidade (CHARNESS et al., 2011). Estes serão chamados aqui simplesmente de Outros. Além da capacidade de transmitir entre si fatos e percepções mais neutras, os Outros também podem transmitir suas opiniões. Ao perceberem direta ou indiretamente as ações do Sujeito, os Outros podem avaliá-las e comunicar de volta ao grupo sua avaliação. Ao fazer isso, contribuem para a formação da Reputação do Sujeito, que será, então, o produto deste processo.

A Reputação do Sujeito é uma medida subjetiva que consolida as variadas avaliações que cada indivíduo confere a este ao longo do tempo sobre um deter- 
minado aspecto. Assim, uma pessoa pode melhorar de reputação ao longo do tempo, bem como ter reputações diferentes em assuntos diferentes. Mais do que apenas uma medida, a Reputação atua também como controlador do sistema, retroagindo sobre os indivíduos (WHITMEYER, 2000; RESNICK et al. 2000). Ao perceber sua Reputação, o Sujeito tem a oportunidade de modificar suas ações, com vistas a administrar esta variável. Também os Outros são afetados por esta medida. Ao comunicarem suas avaliações, estes interferem na percepção dos demais sobre o sujeito, o que acaba por influenciar seu julgamento. Por fim, a memória destas avaliações condicionará seus julgamentos futuros (SANTOS et al. 2011, SANTOS; WEDEKIND, 2015; BERNARD, 2015).

Uma característica do sistema que fica implícita, ou ao menos subexplorada, nos trabalhos revisados é a influência de códigos de conduta nos processos de reputação. Tais códigos podem ser explícitos como aqueles convencionados pelas leis, ou implícitos como os códigos morais e éticos, convencionados pela cultura. Esses códigos de conduta são produtos de outros sistemas sociais complexos, mas que influenciam tanto as ações do Sujeito quanto o julgamentos dos Outros. Ainda que um indivíduo possa subverter ou trocar seus próprios códigos morais, ou mesmo que a sociedade atualize seus códigos legais em função de algum tipo de reputação, os processos gerais do Sistema de Reputação não os controlam. Por isso estes elementos serão posicionados fora do sistema. Nas simulações de cooperação encontradas há algumas regras de pontuação que parecem representar estes códigos de conduta. Um determinado comportamento considerado bom recebe um valor positivo, enquanto o comportamento divergente é pontuado negativamente ou em alguns casos punido de outras formas (TANIMOTO, 2007, SANTOS, WEDEKIND, 2011). Porém, casos reais podem ser mais ambíguos. A manipulação de comentários em sites de vendas relatada por Ye et al. (2014) não é ilegal, mas sim imoral, pois vai contra o que se espera dos vendedores. Já o comportamento agressivo de detentos em um complexo prisional, estudados por Bernard (2015), passa a se tornar a norma local, invertendo os valores esperados.

Visualiza-se, assim, o Sistema de Reputação como um sistema cibernético, ou seja, que possui um processo retroativo que é capaz de alterar seu próprio comportamento a cada iteração. É também um sistema aberto, que recebe influência dos códigos de conduta legais e morais. É composto por um Sujeito que age sobre objetos, conectado reciprocamente a Outros pela comunicação. Também através da comunicação, os Outros formam, disseminam e preservam suas avaliações. O produto deste processo é uma medida da Reputação do Sujeito, que 


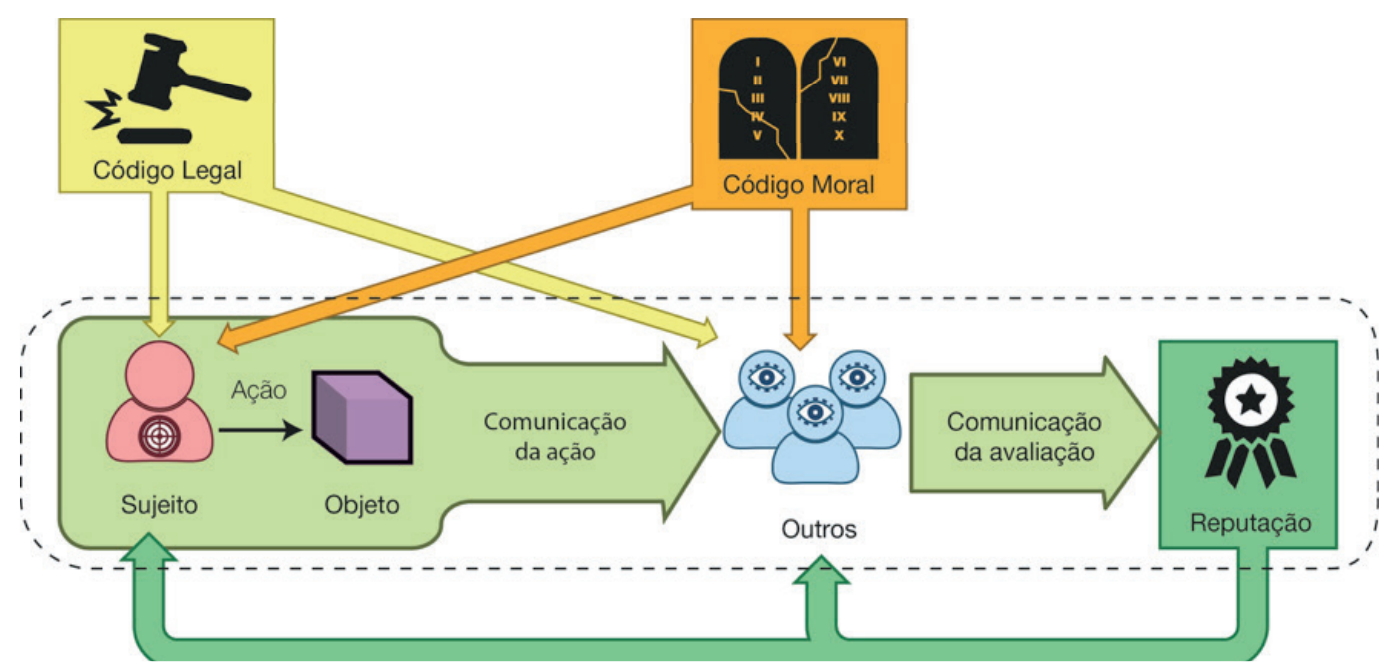

Figura 1. Modelo genérico do sistema de reputação com foco em um sujeito.

Fonte: elaborado pelo autor.

Esta forma de visualização é particularmente interessante no estudo de narrativas pois permite substituir seus elementos pelos da obra que se deseje estudar, verificando as alterações nas relações entre eles. A Figura 2, a seguir exemplifica este método aplicando-o à conhecida lenda de Robin Hood.

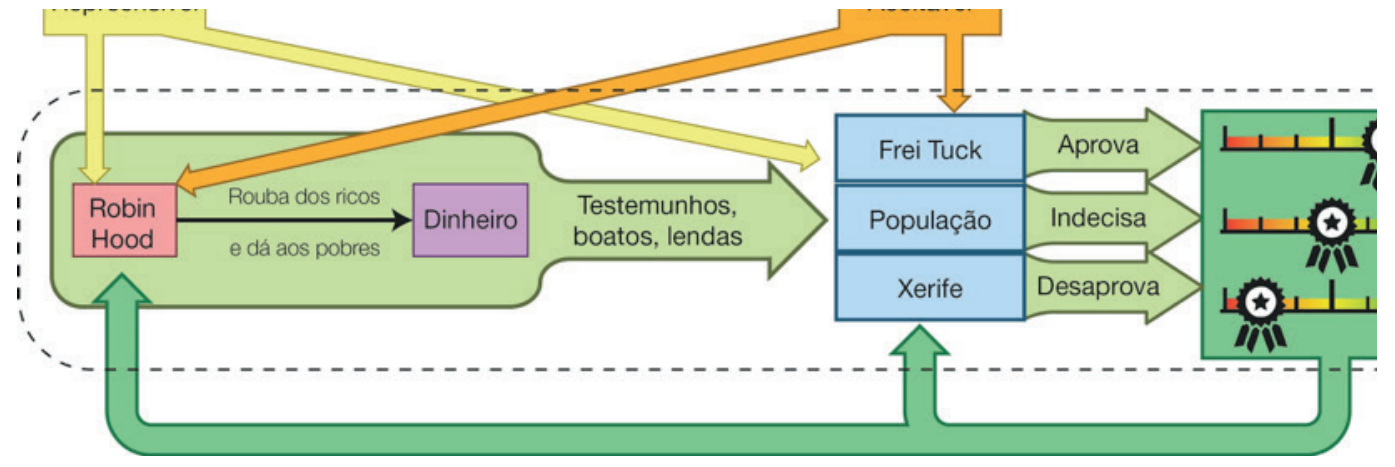

Figura 2. Modelo de Sistema de Reputação aplicado à lenda de Robin Hood.

Fonte: elaborado pelo autor.

A imagem apresenta uma síntese visual do enredo. Nele o Sujeito, Robin Hood, levado por suas próprias percepções sobre certo e errado, age sobre um objeto, o dinheiro dos ricos, dando-o aos pobres. Esta ação é comunicada a outras pessoas através de testemunhos, boatos e lendas. Cada pessoa avalia o que ouve a partir de seus princípios e códigos de conduta pessoais. O caridoso Frei Tuck admira a ação do sujeito contra a avareza dos ricos, enquanto o ganancioso Xerife a considera a pior das afrontas. A população de Nottingham, em geral, se vê indecisa frente o conflito entre legalidade e moralidade, que é o apelo deste conto. Ao expressarem suas opiniões, por quaisquer meios, os Outros ajudam a construir a reputação de Robin Hood, influenciando-o em suas próximas ações, 
e também a própria percepção da população sobre futuras notícias sobre o príncipe dos ladrões. Ao aplicar este modelo em casos específicos é possível identificar os papéis dos indivíduos no processo e as relações de comunicação entre eles. Se neste exemplo, fosse colocado na posição de sujeito, o personagem Frei Tuck, este seria avaliado principalmente por sua ação de apoio ao bando de Robin Hood.

\section{SISTEMAS DE REPUTAÇÃO NOS VIDEO GAMES}

A partir da identificação da estrutura e função do Sistema de Reputação social, serão analisados dois RPGs digitais que exploram a reputação do protagonista em suas narrativas interativas. Ambos os jogos implementam a reputação como um sistema dinâmico, fazendo com que o jogador a leve em consideração durante suas partidas. Além disso, ambos tentam simular aspectos mais subjetivos deste fenômeno. Cada jogo será brevemente explicado e analisado apenas em seus aspectos relevantes para o estudo em questão.

\subsection{DRAGON AGE: INQUISITION (BIOWARE, 2015)}

Neste RPG de fantasia medieval, os jogadores controlam um personagem principal que é a única ou único sobrevivente de um atentado a uma convenção político religiosa, do qual é também o principal suspeito. Ao ajudar a desvendar o ocorrido, o personagem passa a ser considerado um messias, ganhando importância e poder no mundo do jogo, inevitavelmente assumindo o cargo de "Inquisidor" da religião Chantry. Nesta posição, o personagem deverá então tomar parte em disputas políticas, militares e conflitos de interesse entre os habitantes deste mundo fantástico, buscando expandir e exercer a influência desta religião sobre diversos povos e facções.

O sujeito do sistema em questão é portanto este protagonista, um novo líder político, militar e religioso, que será foco da atenção constante dos habitantes de Thedas, considerados aqui como os outros. Thedas é um mundo enorme e populoso, dividido em vários reinos, comunidades e tribos. Todos os habitantes são capazes de reagir a um encontro com o protagonista de acordo com a reputação que este tem para eles. Doze personagens principais são mais elaborados e podem interagir de maneiras mais diretas e complexas com o Inquisidor, avaliando-o sob um ponto de vista particular, podendo aliarem-se a este e até mesmo envolverem-se romanticamente. Já para a maioria dos NPCs encontrados pelo mundo, a reação destes depende de uma reputação geral que o sujeito possui com seu grupo social. Esta reputação geral com determinados grupos é 
obtida principalmente através de interações com alguns personagens especiais que são líderes ou representantes destes grupos sociais.

Dentre as inúmeras possibilidades de ações do jogador, serão aqui considerados objetos apenas aqueles cuja interação com o protagonista resulta em variação da reputação deste. Com isto percebe-se que os principais objetos da ação no sistema de reputação de Dragon Age: Inquisition (DA:I) são justamente este líderes e personagens principais. A reputação do personagem não é tão afetada por suas ações sobre o ambiente, como matar dragões, quanto é por suas ações políticas. Dentre as atividades do Inquisidor estão julgamentos públicos e missões diplomáticas. Estes casos exemplificam como se dá a comunicação das ações que informam as opiniões no mundo do jogo. Ao decidir a pena de um prisioneiro, os aliados emitem opiniões que variam em seis graus de intensidade, três negativos e três positivos, ficando omissos os que são neutros à decisão. Tais opiniões são indicadas ao jogador através de mensagens no display e das próprias falas dos personagens. Outras consequências da decisão podem ser observadas no comportamento e diálogos dos demais NPCs. Condenar um mago ao ostracismo, por exemplo, pode afetar negativamente a reputação do protagonista com todos os outros magos do reino. Já nas missões diplomáticas, o Inquisidor é informado, através de correspondência escrita, sobre alguma situação em cidades distantes. Sua ação envolve escolher e destacar o melhor aliado para resolver o caso. Cada aliado tratará o assunto de maneira diferente, gerando resultados diferentes e diferentes percepções do líder da cidade sobre o Inquisidor. Dessa forma, DA:I apresenta mais um tipo de reputação indireta, conforme identificado na literatura, onde o sujeito é avaliado a partir da intermediação de terceiros. $\mathrm{O}$ apoio dos povos de Thedas à causa do protagonista pode ser visto tanto em suas demonstrações públicas de apoio quanto na adoção das bandeiras da Inquisição. $O$ jogador pode identificar em um mapa o estado de sua influência na região. Já em relação aos personagens principais, o jogador deve identificar através dos diálogos, qual o grau de afinidade com eles naquele momento. $\mathrm{O}$ sentimento dos aliados se modifica de acordo com decisões do jogador, a partir dos interesses e alinhamentos particulares destes personagens. Eles podem se encontrar em um de cinco estados que variam de amigável a hostil, podendo chegar aos pontos de ou cortarem relações com o protagonista, ou passar para uma relação mais íntima. Assim, ao exigir do jogador que interprete as reações dos outros em busca de deduzir seus sentimentos, o jogo busca uma aproximação maior da subjetividade de um sistema de reputação real.

Pelo desenrolar da narrativa e principalmente através dos diálogos é possível 
identificar os Códigos de Conduta subjacentes às relações entre personagens em DA:I. Há forte presença de religiões, seitas, raças e culturas diferentes bem como classes sociais, e estes fatores determinam predisposições dos personagens. Os aliados mudarão seu grau de aprovação do protagonista caso ele tome decisões que favoreçam sua raça, classe ou credo, ou poderão atacar à primeira vista, caso decida contra esta. Sendo apontado como o messias da religião Chantry, o Inquisidor fica ao mesmo tempo submetido à uma doutrina religiosa que precisa expandir, e de certa forma acima das leis, podendo agir de maneiras imorais e violentas, com poucas restrições.

A Função do Sistema de Reputação em DA:l é permitir ao protagonista monitorar a expansão da Inquisição sobre o mundo de Thedas, através de sua influência sobre os demais líderes. Também funciona como um termômetro de suas relações com seus aliados, ajudando-o a se comportar de maneira a mantê-los próximos.

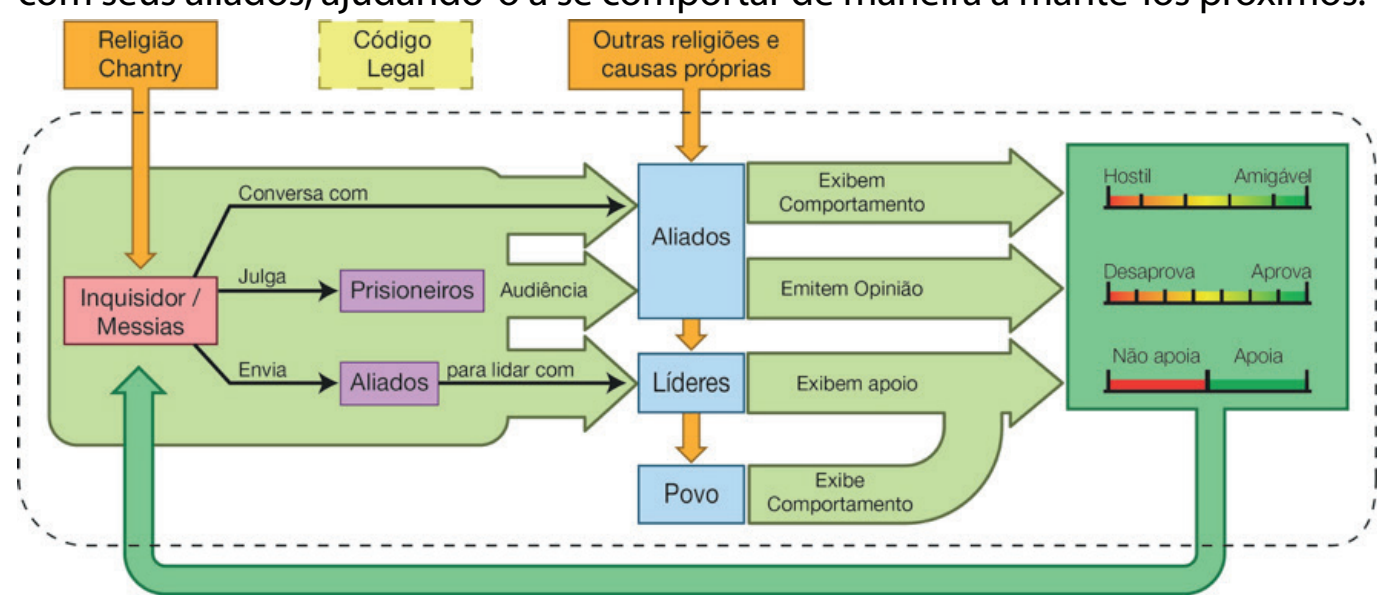

Figura 3. Modelo do Sistema de Reputação de Dragon Age: Inquisition.

Fonte: elaborado pelo autor.

\subsection{FABLE III (LIONHEAD STUDIOS, 2009)}

O sujeito, neste outro RPG, é um príncipe ou princesa, controlado pelo jogador, que se vê compelido a iniciar uma rebelião contra seu irmão tirano. Durante a fase de preparação da rebelião, o jogador deve conquistar o apoio de diversas comunidades do reino e seus respectivos líderes, ajudando-os em suas causas e comprometendo-se a ajudá-los ainda mais quando ocupar o trono. A partir do ponto em que este objetivo é alcançado e o jogador se torna o rei de Albion, este passa lidar com a administração das finanças do reino e os conflitos de interesses de seus súditos. Durante o período de um ano, no tempo do jogo, o personagem deverá levantar dinheiro suficiente para preparar seu reino contra uma invasão já anunciada. As escolhas feitas para atingir este objetivo final, co- 
locam o personagem em uma encruzilhada: tomar medidas populares mas que coloquem em risco a segurança de todos, ou priorizar os gastos com a defesa sob o risco de ser visto também como tirano.

Não apenas os principais, mas cada NPC de Fable III possui uma opinião particular sobre o protagonista. Embora a opinião de um grupo geralmente acompanhe a de seu líder ou representante, cada habitante do reino pode possuir sentimentos positivos ou negativos em relação ao jogador, com a possibilidade de serem desposados pelo protagonista. Novamente, alguns NPCs mais importantes e elaborados, poderão tornar-se aliados do príncipe rebelde, passando a aconselhá-lo no futuro. Porém os objetos da ação que resultam em reputação para o protagonista não são apenas outros personagens, mas uma maior gama de comportamentos no mundo do jogo. A maneira como o jogador administra os recursos do reino e suas reservas pessoais, suas escolhas de roupas e mesmo hábitos alimentares, influenciam em sua imagem pública.

A comunicação recebe uma atenção especial em Fable III. Além de opções de diálogo, tenta-se simular uma comunicação não-verbal. Interagindo com um NPC, o jogador pode também escolher entre opções de gestos e movimentos. As instruções no jogo indicam que algumas opções permitem que o jogador controle a intensidade ou duração do gesto, para chegar em um ponto ideal. Assim, um aperto de mão pode ser demasiado curto ou inconvenientemente longo, afetando a percepção do NPC sobre o personagem. O jogo também tenta indicar a importância dos meios escritos e impressos. Determinados grupos ou personagens exigem que o protagonista prometa que observará seus interesses no futuro. Esta promessa é feita na forma de uma declaração por escrito e assinada, que é exibida ao jogador no momento do aceite. Posteriormente, quando este se torna monarca, as necessidades do reino podem levá-lo a quebrar tais pactos, prejudicando sua reputação geral. Há ainda um detalhe nas telas de carregamento do jogo. Nelas são apresentados cartazes que estariam espalhados pelo reino a cada momento. No início da aventura exibem-se anúncios com as exigências impostas pelo regente, que posteriormente surgem pichados, conforme a população adota a rebelião. Revelam-se cartazes oficiais denunciando os personagens insurgentes, aliados do protagonista, e mais adiante na trama são exibidas as publicações em ovação ao novo líder.

$O$ jogador pode medir a reputação de seu personagem observando uma espécie de régua que aparece sob cada NPC que encontra. Esta mostra quanto o personagem está simpático ou antipático ao protagonista. Mas apesar desta exibição linear, as variáveis de controle neste jogo são mais diversas. Primei- 
ramente não há apenas uma reputação boa ou má. O personagem principal é avaliado em escalas que variam entre Moral e Imoral; Rico e Pobre; Amor e Temor; Bonito e Feio. Há ainda uma escala de corrupção, que começa em zero, significando pureza de comportamento, e que pode aumentar dependendo das atitudes do jogador. Cada NPC possui uma predisposição e interesse em determinadas características, de forma que a combinação destas medidas afeta a opinião individual sobre o protagonista. Assim Fable III tenta ser mais realista no que tange às opiniões individuais e plurais dos outros.

Entretanto, essa pluralidade mostra-se sem profundidade uma vez que os Códigos de Conduta, em especial a moralidade das decisões é simulada de forma binária. As opções do jogador aparecem explicitamente identificadas como sendo morais ou imorais, sendo as primeiras envoltas em uma aura branca e as últimas envoltas em chamas. Quando o jogador tem de julgar um conflito de interesses, os apelos de seus companheiros mais próximos são geralmente brilhantes, e os dos arguentes, geralmente flamejantes. Isso, reforçado por uma resposta homogênea da opinião pública sobre a questão, retira a ambiguidade das decisões, invalidando a posição do arguente. Em resumo, em Fable III cada habitante tem uma opinião diferente sobre o protagonista a partir da interação em primeira mão que trava com este, mas não divergem entre si a respeito das decisões deste como líder. Também apesar de algumas indicações sobre a existência de leis, estas não são muito exploradas, uma vez que durante a primeira metade do jogo o personagem é um rebelde fora da lei, e na outra é um monarca com amplas liberdades.

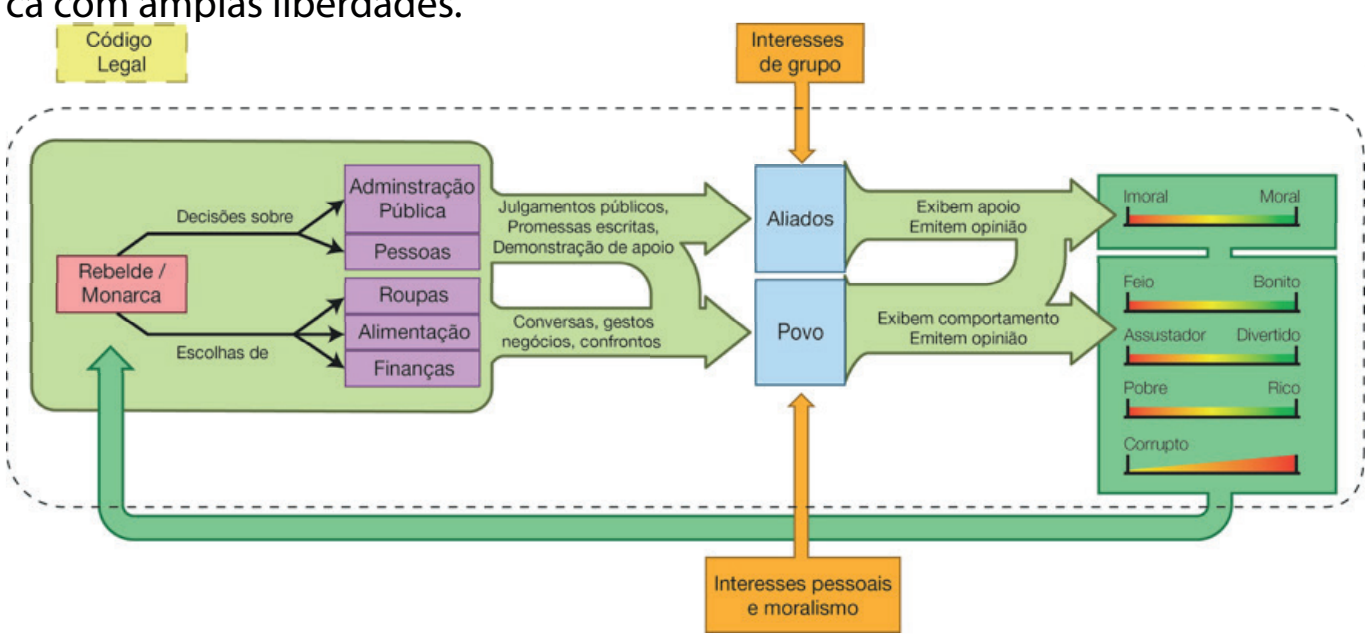

Figura 4. Modelo do Sistema de Reputação de Fable III. Fonte: elaborado pelo autor.

\section{COMPARAÇÃO DOS CASOS}

A partir da modelagem de um sistema de reputação básico, fundamentado 
nas informações encontradas na literatura, foi possível prever subsistemas básicos e definir um processo padrão. Este processo foi expandido e detalhado de acordo com os casos, dando visibilidade aos processos de comunicação que ocorrem e quais personagens da narrativa digital estão envolvidos. As principais diferenças não foram encontradas no fluxo do processo, mas nas variáveis deste. Os jogos, portanto, não apresentam um mesmo sistema de reputação, mas sim adaptações criativas do sistema geral, moldadas de acordo com o pretendido para cada enredo.

Um aspecto semelhante a ambos é que, diferentemente do observado no mundo real, a função do Sistema de Reputação nos jogos não parece ser a de regular o sistema social nem mesmo de coibir ações indesejáveis. Pelo contrário, serve para criar um desequilíbrio interessante para a trama. O mundo do jogo parece estável, até que o jogador comece a interagir, agradando ou desagradando NPCs, construindo uma reputação para si. Os protagonistas não seguem algum ideal de conduta, e tão pouco são impelidos a tornarem-se referência para os demais personagens. A reputação passa a ser um recurso do indivíduo que o permite interagir de novas maneiras com os outros e assim alcançar seus objetivos Também a comunicação parece funcionar de maneira diferente. Enquanto no cotidiano real há uma múltipla interferência de meios de comunicação na formação das opiniões, nos jogos isso é drasticamente simplificado em função de estabelecer uma variável de tratamento mais simples. Os jogos suprimem os efeitos dos ruídos da comunicação boca-a-boca e em massa, e também do tempo para a disseminação das informações. Sugerindo uma onisciência cômoda. Todos os habitantes sabem exata e imediatamente o que tiver acontecido, e as opiniões de um NPC não afetam as de outro. Outra face da mesma moeda, é a onisciência do indivíduo sobre sua própria influência nos outros. Os jogos informam imediatamente ao jogador os efeitos de suas ações, algumas vezes antecipadamente. $\mathrm{O}$ que confere ao protagonista um super poder de decisão, monitoramento e controle sobre sua própria reputação. Nestes jogos praticamente não há desinformação. O sujeito sempre sabe o que os outros pensam sobre ele e os outros sempre julgam-no a partir dos fatos.

Na mesma direção segue o tratamento dos códigos de conduta. As duas narrativas indicam a existência de sistemas religioso e legal, porém a complexidade do segundo é pouco explorada. Os jogos se passam em mundos fantásticos, que podem compensar a simplificação de tais sistemas. Ambos os protagonistas, quando ocupam os cargos de Inquisidor ou de Rei, passam a ser a própria Lei, minimizando os efeitos coercitivos que essa poderia ter sobre eles. A moralida- 
de no entanto é mais forte,principalmente em DA:I. NPCs julgarão as atitudes do protagonista com base em convenções e inclinações sobre certo e errado, mas apesar de haverem algumas discordâncias entre eles, há uma homogeneidade em suas visões de mundo. Os ambientes destes jogos e suas civilizações, apesar de vastos, diversificados e detalhados, são populados por indivíduos que compartilham opiniões muito próximas sobre certo e errado.

\section{CONSIDERAÇÕES FINAIS}

Considera-se então, que no âmbito das narrativas interativas, os comportamentos e fenômenos sociais são modelados de forma a sancionarem os objetivos narrativos. O sistema de Reputação Social, usado como exemplo, é hora bem detalhado, hora simplificado, mantendo os aspectos mais convenientes para os autores. Certamente, tais mudanças e concessões são feitas para permitir que a narrativa se desenvolva como esperado, trazendo maior prazer e satisfação para os jogadores. Para cumprir seus objetivos de transmitir uma mensagem e ainda permitir controle e decisão aos jogadores, os autores de narrativas interativas, precisam decidir o grau de liberdade que seu mundo fictício comporta. Ao decidirem quais variáveis serão incluídas e seu comportamento, os autores direcionam a narrativa e a ação dos jogadores para a experiência desejada. A simulação do fenômeno social não é feita com vistas a permitir uma experiência completa e realista da situação, mas uma experiência real o suficiente para que os jogadores possam brincar com ela, experimentando seus efeitos sem perder a imersão necessária para o enredo. Mostrando, assim, como a modelagem de sistemas sociais comporta criatividade, configurando-a como um meio de comunicação e expressão.

\section{REFERÊNCIAS}

ALVES, J. B. M. Teoria geral de sistemas: em busca da interdisciplinaridade. Florianópolis: Instituto Stela, 2012. 179p.

BERNARD, S. The value of vengefulness: Reputational incentives for initiating versus reciprocating aggression. Rationality and Society. Vol. 27(2) pp $129-160.2015$.

BOGOST, I. The Rhetoric of Video Games. The Ecology of Games: Connecting Youth, Games, and Learning. Katie Salen (Ed). The John and Catherine T. MacArthur Foundation Series on Digital Media and Learning. Cambridge, MA: The 
MIT Press, pp.117-140. 2008.

BUENO, F. S. Minidicionário da Língua Portuguesa. São Paulo: FTD. 1996. CHARNESS, G.; Du, N.; Yang, C. Trust and trustworthiness reputations in an investment game. Games and Economic Behavior 72, pp 361-375. 2011.

CROOKAL, D. Philosophy and Simulation. Simulation \& Gaming, Vol. 42(2), pp.146-150. 2011.

DORMANS, J. Beyond Iconic Simulation. Simulation \& Gaming, Vol. 42(5), pp.610-631. 2011.

GALVÃO, C.; SAWADA, N.;TREVIZAN, M. Revisão sistemática: recurso que proporciona a incorporação das evidências na prática da enfermagem. Rev Latino-am Enfermagem, maio-junho, 2004.

GOOGLE.Resultadoda pesquisa por"reputação".Disponívelem <https://www.google.com.br/webhp?sourceid=chrome-instant\&ion=1\&espv=2\&ie=UTF-8\#q=reputa\%C3\%A7\%C3\%A3o> acesso em 13/04/2017.

GREDLER, M. Games And Simulations and Their Relationship to Learning. Games/Simulations and Learning. In Handbook of research for educational communications and technology , 2a ed., pp 571-581. Editado por: Jonassen, D.. Mahwah, NJ: Lawrence Erlbaum Associates. 2014.

HONG, S. When Life Mattered: the politics of the real in video game's reappropriation of History, Myth, and Ritual. Games and Culture. Vol 10(1) pp 35-56. 2015.

INBAR, M. Editorial Introduction. Simulation and Gaming, Vol 1(1), pp 3-4. 1970. LEWIS, C. T; SHORT, C. A Latin Dictionary. Oxford: Clarendon Press. 1879. Disponível em: $<$ http://www.perseus.tufts.edu/hopper/text?doc=Perseus:text:1999.04.0059:entry=reputo > acesso em 07/04/2017.

RESNICK, P.; ZECKHAUSER, R.; FRIEDMAN, E.; KUWABARA, K. Reputation Systems. Communications of the ACM. Vol 43(12) pp. 46-48 2000. 
ROBINSON, S. A Tutorial On Conceptual Modeling for Simulation. Proceedings of the 2015 Winter Simulation Conference, pp 1820-1834. Editado por: L. Yilmaz, W. K. V. Chan, I. Moon, T. M. K. Roeder, C. Macal, and M. D. Rossetti. 2015.

SAEEDI, M. Essays on Reputation. Tese de Doutorado em Filosofia, University of Minnesota, Minneapolis -MN, EUA. 2012.

SALEN, K.; ZIMMERMAN, E. Regras do Jogo: fundamentos do design de jogos. Vol 1. São Paulo. Blucher. 2012.

SANTOS, M.; RANKIN, D. J.; WEDEKIND, C. The evolution of punishment through reputation. Proceedings of the Royal Society B. Vol 278, pp. 371-377. 2011 SANTOS, M.; WEDEKIND, C. Reputation based on punishment rather than generosity allows for cooperation in sizable groups. Evolution and Human Behavior. Vol 36 pp. 59-64. 2015.

TANIMOTO, J. A study of indirect reciprocity involving a reputation system or a simple tag system in a one-shot, multi-player game. BioSystems. Vol 90, pp. 856-869. 2007.

WEINBERG, B. D; DAVIS, L. Exploring the WOW in online-auction feedback. Journal of Business Research, 58, pp 1609-1621. 2004.

WHITMEYER, J. M. Effects of positive reputations systems. Social Science Research, Vol 29, pp. 188-207. 2000.

YE, S.; GAO, G.; VISWANATHAN, S. Strategic Behavior in Online Reputation Systems: Evidence From Revoking on eBay. MIS Quarterly Vol 38 (4), pp 10331056. 2014.

Gertrudes Aparecida Dandolini é Mestre (1997) e Doutora em Engenharia de Produção pela Universidade Federal de Santa Catarina (2000), e licenciada em Matemática pela Universidade Federal de Santa Catarina (1992). Foi professora da Universidade Federal de Pelotas entre 2003 e 2007, onde foi coordenadora do curso de Matemática e do curso de Matemática na modalidade a distância. Foi pesquisadora da Universidade Aberta do Brasil (UAB) até 2011. Atualmente é Professora Titular da Universidade Federal de Santa Catarina do Departa- 
mento de Engenharia do Conhecimento, um dos líderes do Grupo de Pesquisa IGTI e do ENGIN - Engenharia da Integração e Governança do Conhecimento. Na graduação tem trabalhado com a disciplina de Teoria Geral dos Sistemas, Criatividade e Inovação e Gestão da Inovação. Na pós-graduação é professora do Programa de Pós Graduação em Engenharia e Gestão do Conhecimento da UFSC na área de inovação. Área de pesquisa atua principalmente com: Front End da Inovação, Inteligência para Inovação, Gestão de Inovação, Inovação Social e Universidade Corporativa. http://lattes.cnpq.br/3098548295086867.

Rafael Arrivabene é mestrando em Engenharia e Gestão do Conhecimento pela UFSC, na área de concentração Mídia e Conhecimento. Estuda retórica procedimental, linguagem video lúdica e análise da significação em jogos. Possui título de bacharel em Desenho Industrial pela UNESP e cursou especialização em desenvolvimento de jogos pelo SENAC-SP. Atuou como gerente de criação multimídia na empresa MStech, onde supervisionou o desenvolvimento de jogos educativos, objetos de aprendizagem e cursos online gamificados de 2010 até o fim de 2014. Atualmente trabalha como game designer freelancer em jogos de entretenimento e educacionais, digitais e analógicos. 